\title{
CRENÇAS E CONCEPÇÕES DO TRADUTOR EM FORMAÇÃO'
}

\author{
Marileide Dias Esqueda \\ Karoline Izabella de Oliveira
}

Dentre os vários fatores que influenciam o processo de ensino e aprendizagem, encontram-se as crenças que os alunos trazem consigo para a sala de aula e que, segundo os pesquisadores, direcionam o quê, como e quando o aluno decide aprender.

As crenças podem ser entendidas, nas palavras de Barcelos e Vieira Abrahão (2006), como uma forma de pensamento, como construções da realidade, maneiras de ver e perceber o mundo e seus fenômenos, co-construídas em nossas experiências e resultantes de um processo interativo de interpretação e (re)significação. Para as autoras, as crenças têm origem social e também individual; são dinâmicas, contextuais e paradoxais, já que podem mudar de acordo com o contexto social no qual cada um se encontra inserido.

Presente nas reflexões acerca dos processos de ensino e aprendizagem, o estudo sobre as crenças pode ser encontrado e aplicado a quaisquer contextos.

No campo da Matemática, por exemplo, Ferreira (1998) defendeu uma dissertação de mestrado com o título "O desafio de ensinar-aprender matemática no curso noturno: um estudo das crenças de estudantes de uma escola pública de Belo Horizonte".

A autora investigou quais as crenças dos estudantes em relação à Matemática, seu ensino e aprendizagem e que relações existem entre essas crenças, o desempenho e a autoestima desses alunos. Os resultados mostraram que os alunos possuíam uma visão utilitarista da Matemática, na qual os conteúdos somente são considerados importantes quando se mostram úteis à vida cotidiana: seja em problemas do dia-a-dia ou em

\footnotetext{
${ }^{1}$ Este trabalho é parte integrante da pesquisa "O Professor de Tradução: Desdobramento de competências e perfis", cadastrado e desenvolvido no Instituto de Letras e Linguística da Universidade Federal de Uberlândia (Processo ILEEL/080/2010), sob a responsabilidade da Prof ${ }^{a}$ Dr $^{a}$ Marileide Dias Esqueda. Os dados sobre as crenças dos alunos de tradução coletados nesta pesquisa serão posteriormente confrontados com os dados sobre as crenças dos professores de tradução, buscando-se desvendamentos, discussões e possíveis ações futuras para o ensino e aprendizagem de tradução. Agradecemos à ProppUFU e ao CNPq/PIBIC pela concessão de bolsa de Iniciação Científica à aluna Karoline Izabella de Oliveira.
} 
exigências profissionais e acadêmicas. A pesquisa também apontou que a interação professor-aluno é vista como essencial neste processo. Aos professores, entretanto, fica reservado apenas o papel de amigo, atento e paciente, disposto a repetir quantas vezes forem necessárias para que todos aprendam. Outro dado igualmente interessante da pesquisa é o de que persistem as influências das condições socioculturais sobre a aprendizagem da Matemática, isto é, de que se trata de uma disciplina difícil de ser ensinada e aprendida.

Ainda na área de Matemática, alguns anos depois, Motta (2005), em seu estudo sobre a dimensão afetiva em educação matemática, ao investigar as crenças trazidas por alunos ingressantes do Curso de Matemática, ressalta a importância de estudos nessa vertente. Segundo a pesquisadora, a conscientização das crenças pelo aprendiz pode servir como um elemento de autorregulação e para aumentar a responsabilidade e autonomia do aluno. Observar as emoções, atitudes e crenças do aluno em relação à Matemática oferece indícios das experiências que este teve como estudante, da perspectiva profissional e da sensibilidade social do contexto em que o ensino se desenvolve. Os conhecimentos subjetivos pertencentes às crenças dos professores se traduzem em sua maneira de ensinar, do mesmo modo que os pertencentes às crenças dos alunos se traduzem em bloqueios e resistências a alguns tipos de aprendizagem. As exigências afetivas para a aprendizagem devem ser tão estudadas quanto as exigências cognitivas, pois a imagem que os alunos e os professores têm podem servir como referência para novas estratégias de ensino e como crítica para certos métodos.

Rodriguez et al. (2000) investigou as crenças sobre o ensino e aprendizagem na área de Química. O objetivo da pesquisa foi detectar as crenças de cidadãos e de estudantes de ensino médio sobre o papel da química no mundo contemporâneo, no intuito de comparar as representações advindas desses dois grupos e analisar o papel da escola na construção deste conhecimento. Os resultados mostraram que a química formal apresentada pela escola, aos olhos dos dois grupos, se reduz à transmissão de informações, definições e leis isoladas. Os alunos parecem ter dificuldade em relacionar a Química que aprendem na escola com a vida, reduzindo sua importância ao atribuir sua utilidade principalmente para passar no vestibular.

$\mathrm{Na}$ área de Linguística Aplicada, estudos como os de Viana (1993); Gimenez (1994); Barcelos (1995); Carvalho (2000); Nicolaides e Fernandes (2002); Silva (2005); Barcelos e Vieira-Abrahão (2006); Esqueda e Fratine (2011), mostram como os 
pensamentos e concepções construídas pelos alunos podem influenciar na aquisição das competências linguístico-comunicativas.

Para os autores, as crenças trazidas pelos alunos dos cursos de Letras com relação ao ensino e à aprendizagem de línguas, ao papel do professor e do aluno em sala de aula e à importância da gramática, influenciam o comportamento do futuro professor de línguas. Muitas vezes, eles acreditam que aprender um idioma é aprender rapidamente, de uma vez, apenas uma série de regras gramaticais e um vocabulário que será guardado na memória como conhecimentos já adquiridos sobre essa língua. Essas crenças conduzem o aluno à escolha de recursos e formas para seu aprendizado e funcionam como um filtro pelo qual passam e são interpretadas. É a interpretação de cada um que determina o que será adquirido e o que será rejeitado, e esta relação determinará a atuação do futuro professor de línguas. Segundo Barcelos (1995), as crenças não são somente um conceito cognitivo, mas também social, porque nascem de nossas experiências e problemas, de nossa interação com o contexto e da nossa capacidade de refletir e pensar sobre o que nos cerca, daí a importância de estudos que as investiguem e que as socializem e discutam junto aos alunos, no intuito de desenvolver uma reflexão e possível conscientização.

Em se tratando da área de tradução, as crenças dos alunos-tradutores também demonstram importância para a reflexão dos estudos realizados na área, principalmente aqueles dedicados à formação de tradutores.

Segundo Pagano (2000):

No caso do aprendiz de tradução, essas percepções filtram as formas de pensar e abordar a tradução e têm um efeito considerável no desempenho do tradutor-aprendiz e no trabalho a ser desenvolvido. Por se tratar de concepções sobre o processo tradutório que podem não se corroborar como adequadas ou positivas, as crenças podem conduzir a uma tradução não adequada ou insuficiente. (p. 10)

A autora defende que o conhecimento prévio que o aluno-tradutor traz para a sala de aula pode favorável ou desfavoravelmente delinear suas percepções:

Como esses pressupostos são parte de um conhecimento prévio, adquirido pelo aprendiz e armazenado como noções de referência, pouco revisadas ou questionadas, as crenças dão lugar a expectativas que, quando não plenamente satisfeitas, produzem ansiedade e sentimento de insucesso e frustração. (p. 10) 
Pagano (2000) expõe ainda que as crenças do aprendiz podem se tornar um ciclo vicioso, ou seja, a crença aparentemente explica o insucesso, ao mesmo tempo o reforça e impede soluções para os problemas vivenciados pelo aprendiz na universidade e, em futuro próximo, no mercado de trabalho:

\begin{abstract}
No caso específico da tradução, as crenças comprovadamente desempenham um papel social mais amplo e, portanto, mais crítico, uma vez que além de influenciar a performance do tradutor, elas também determinam a forma como a sociedade em geral tende a avaliar a tradução como profissão e o tradutor como agente dessa atividade, com base nessas percepções mais divulgadas. (p. 11)
\end{abstract}

As percepções sociais mais comuns sobre a tradução são, segundo a autora, a de que a tradução é uma arte reservada a uns poucos que podem exercê-la graças a um dom especial; que é uma atividade prática que requer um conhecimento da língua e um bom dicionário; que o tradutor deve ser falante bilíngue ou ter morado num país onde se fala a língua estrangeira do par linguístico com que trabalha; de que só se pode traduzir da língua estrangeira para a língua materna, uma vez que só dominamos esta última, e de que todo tradutor é traidor, frase famosa legitimada por todas as épocas e culturas e que subentende certo descrédito sobre a natureza e objetivos da tradução. Ainda, nos dias de hoje, pode-se acrescentar, há a percepção social e dos alunos de que os computadores vão substituir o tradutor.

Logo na introdução de sua obra intitulada Translating Cultures, David Katan (2004), Professor de Tradução na Scuola Superiore de Lingue Moderne Itália per Interpreti e Traduttori da Universidade de Trieste (na Itália), igualmente afirma haver necessidade de se modificar o lugar que os tradutores e intérpretes ocupam no imaginário social. Para o autor, os tradutores são concebidos como "dicionários humanos" ou "copistas", e tal visão necessita ser mudada para que os profissionais possam ser reconhecidos como agentes visíveis do processo de (re)estabelecimento das condições necessárias para a comunicação entre povos e pessoas.

Buscando investigar tal imaginário, Rodrigues (2004) afirma solicitar anualmente a seus alunos da disciplina de Teoria da Tradução que informem se concordam ou discordam de que a tradução é "uma arte reservada a uns poucos que podem exercê-la graças a um dom especial". A autora relata que do universo de $86 \%$ dos que responderam esta e outras perguntas, $6 \%$ concordaram com a afirmação e $6 \%$ não tinham opinião formada a respeito. Ainda, 14\% dos alunos de um curso para formar tradutores não têm certeza de que essa formação é possível. Segundo Rodrigues: 
O conflito apenas se instaura se houver a expectativa de que um curso de teoria da tradução forneça ferramentas de aplicação mais ou menos direta que substituam opiniões, crenças e senso comum por modelos, regras e leis. Esse é o quadro delineado por uma tradição que não considera a tradução como um objeto de estudo legítimo, mas como uma técnica ou um dom. Nesse domínio concebe-se a tradução como um mal necessário, como uma prática de segunda mão; para praticá-la não seria necessário ter qualquer formação específica, bastaria ter o dom, ou conhecer uma técnica. Entretanto, o discurso que exclui a reflexão e o trabalho intelectual da tarefa do tradutor, que o considera um mero aplicador de regras, seguidor de receitas, é o mesmo que embasa a baixa remuneração de seu trabalho. É um discurso que, sem se darem conta, tanto professores quanto alunos endossam, uns quando consideram que a teoria tem lugar secundário na formação do aluno, outros quando esperam que ela forneça todo o instrumental "concreto" para seu trabalho. (p. 81-82)

A possibilidade e impossibilidade do ensino de tradução também foi objeto de pesquisa de Antony Pym (1993). Em seu texto intitulado Epistemological Problems in Translation and its teaching, o autor traça uma abordagem crítica para explicar alguns dos problemas epistemológicos que afetam os princípios do ensino e aprendizagem da tradução. Um dos pontos discutidos por Pym é o de que alunos de tradução trazem consigo, e também levam para a vida profissional, crenças desfavoráveis com relação ao indeterminismo teórico que compõe a natureza da área de tradução. A impossibilidade de se chegar a conclusões palpáveis, tanto em termos teóricos quanto práticos, sobre o que é tradução e o papel do tradutor, desestabiliza a relação do tradutor-aprendiz com a área.

Nesta vertente, Magalhães (1991) também explica haver tal instabilidade nos conceitos e definições sobre a tradução e no papel do tradutor concebidos por tradutores renomados, não somente no Brasil, mas também no exterior.

Milton (2000) também dá tratamento especial às crenças que os alunos ingressantes de Cursos de Graduação em Tradução trazem consigo para a sala de aula. O autor aponta que as crenças sobre o tradutor e a tradução devem ser estudadas com vistas a explicitar a importância destas no desenvolvimento e exercício consciente da prática tradutora. As conclusões oriundas desta pesquisa mostram que os alunos possuem uma crença inicial de que os cursos de graduação em tradução irão apenas propiciar aperfeiçoamento do conhecimento linguístico.

Nessa perspectiva, o propósito deste trabalho é investigar as crenças que os ingressantes do ano de 2011 do recém-criado Curso de Bacharelado em Tradução da Universidade Federal de Uberlândia trazem consigo, uma vez que se almeja o 
desvendamento sobre essas crenças, identificando possíveis ações e procedimentos que possam contribuir para a formação consciente e autônoma de futuros tradutores.

O desvendamento das crenças dos ingressantes justifica-se, científicoacademicamente, por buscar, de acordo com os resultados advindos deste trabalho, possibilidades de intervenção por parte dos docentes do curso e reformulações, se necessário, do processo de ensino e aprendizagem de tradução. Segundo Pagano (2000), as crenças, independentemente de sua natureza, isto é, individual ou coletiva, são passíveis de mudança mediante intermediações de algum agente:

As crenças variam de pessoa a pessoa e estão relacionadas às experiências de cada indivíduo e ao contexto sociocultural com o qual interage. Por se tratar de ideias e pressupostos que o aprendiz formula a partir de sua experiência, as crenças são passíveis de mudança, seja pelo próprio acúmulo de vivências do aprendiz, seja pela intervenção deliberada por parte de algum agente no seu processo de aprendizagem. (p. 11)

Considera-se, portanto, que este estudo possa compor material fidedigno a docentes, discentes e profissionais da área de tradução como um todo. No plano social, a importância desta pesquisa evidencia-se no argumento de que a investigação no âmbito educacional funciona como instrumento capaz de problematizar o processo de ensino e aprendizagem de tradução e de propiciar o debate, contribuindo para possíveis novas propostas de ação na sala de aula.

\section{(Re)Examinando as crenças no ensino e aprendizagem de Tradução}

O tema crenças é de suma importância não apenas para professores, mas também para os próprios alunos, grandes interessados no processo de construção do conhecimento.

Em relação às crenças no ensino e aprendizagem de tradução, adotando-se aqui uma perspectiva cronológica de estudos brasileiros sobre a temática, Lages (1992) já apontava que:

A história da tradução e da imagem do tradutor que tradutores, escritores e críticos construíram pode ser descrita como uma história de rebaixamentos, auto-reproches, enfim de um constante empobrecimento do Ego do tradutor, por um lado; por outro, consiste na afirmação enfática de capacidades sobrehumanas em termos de conhecimentos linguísticos e culturais a serem dominados pelo tradutor, figurando a faceta maníaca da visão tradicional do tradutor e da tradução. (p. 92) 
As afirmações de Lages (1992), assim como as de Katan (2004), fazem com que seja possível constatar que as crenças, pensamentos, expectativas, concepções, ou nome similar que se queira atribuir ao tema, sempre foram de grande importância para a construção do que se pensa sobre a tradução e o tradutor e de como se aprende a traduzir.

Pagano (2000) expõe que "Por crenças, entende-se todo pressuposto a partir do qual o aprendiz constrói uma visão do que já seja aprender e adquirir conhecimento" (p. 9).

Citando Butler \& Winne (1995)², Pagano (op.cit.) argumenta que todo aprendiz possui uma série de crenças a respeito do que é aprender: como se aprende, qual o esforço a ser despendido nessa tarefa e com que velocidade são assimilados os conhecimentos:

Orientado pelas suas crenças, o aprendiz decide o que aprender, como, quando e em quanto tempo. Crenças que refletem adequadamente o processo de ensino/aprendizagem geralmente conduzem o aprendiz à escolha de recursos e formas apropriadas que, por sua vez, garantem o sucesso e o contínuo exercício de procedimentos acertados. Por outro lado, crenças errôneas ou pouco fundamentadas levam o aprendiz a optar por recursos e formas não apropriados e culminam, geralmente, no insucesso e na insatisfação. (p.9)

Pagano (2000) define e discute algumas das crenças mais comuns no âmbito do ensino e aprendizagem da tradução:

- A tradução é uma arte e reservada e uns poucos que podem exercê-la graças a um dom especial. Para a autora, está implícita aqui a ideia de que se nasce tradutor ou de que só pode chegar a sê-lo quando se possui este dom. Pagano aponta que as pesquisas mostram que tradutores competentes e reconhecidos possuem uma carreira que envolve experiência e qualificação.

- A tradução é uma atividade prática que requer apenas um conhecimento da língua e um bom dicionário. Na visão de Pagano (2000), a formação requer o desenvolvimento de habilidades que transcendem o conhecimento meramente linguístico: "Dentre essas habilidades ressaltam-se a busca de subsídios externos, isto é, de informações e conhecimentos necessários à recriação do

\footnotetext{
2 BUTLER, D.; WINNE, P. Feedback and self-regulated learning: A theoretical synthesis. Review of Educational Research, v.65, n.3, p.245-281, 1995.
} 
texto, e a utilização de recursos tecnológicos que comprovadamente aprimoram a tradução" (p. 13).

- O tradutor deve ser falante bilíngue ou ter morado num país onde se fala a língua estrangeira do par linguístico com que trabalha. Segundo Pagano (2000), alguns falantes bilíngues exercem a tradução com sucesso, bem como alguns tradutores que possuem vivência de alguma das culturas em que se fala a língua estrangeira:

\begin{abstract}
No entanto, os estudos também mostram que nesses casos, o bilinguismo ou a vivência do tradutor estão acompanhados de uma formação que lhe permite o bom desempenho como tradutor. Não devemos esquecer que o falante bilíngue pode ter um domínio limitado das línguas que fala ou pode não contar com alguns dos outros aspectos que fazem parte da chamada "competência tradutória". (p.13)
\end{abstract}

- Só se pode traduzir da língua estrangeira para a língua materna, uma vez que só dominamos esta última. Segundo Pagano (2000), o fato de sermos falantes nativos de uma língua não nos habilita automaticamente a traduzir para essa língua. Confirmando o dito anteriormente, a autora argumenta a tradução requer uma formação e uma qualificação que fornecem ao tradutor as habilidades e conhecimentos suficientes para uma boa performance:

Nesse sentido, o domínio de uma língua estrangeira juntamente com o conhecimento cultural, técnico, e as habilidades apropriadas para o exercício da recriação de um texto, possibilitam a tradução para a língua estrangeira sem maiores problemas. Questões mais complexas, como a das coligações textuais e as tipicidades do falante nativo, estão hoje muito próximas de serem resolvidas graças ao desenvolvimento de bancos de dados de coligações e combinações mais frequentes numa língua e numa cultura. (p. 14)

- Traduttori, traditori. Pagano (2000) expõe que a problematização dessa crença tem recebido suporte maior a partir das teorias que redefinem a natureza e o objetivo da tradução, sobretudo, com a consolidação da disciplina Estudos da Tradução a partir dos anos de 1980. A partir do que é discutido pela autora, a ideia de "traição" pressupunha, dentre outras coisas, uma outra crença também ainda bastante disseminada, de que se traduz num vácuo temporal e cultural, no qual uma ideia formulada numa língua pode ser automaticamente transposta em outra língua como se tratasse de uma operação matemática de equivalências entre palavras mediadas por um dicionário. 
Para Pagano (2000):

Podemos dizer que há uma relação estreita entre as crenças do aprendiz, as estratégias que ele escolhe e utiliza e o maior ou menor sucesso de seu desempenho. A crença de que traduzir seja simplesmente transpor o significado de palavras com a ajuda de um dicionário pode levar o tradutor a utilizar estratégias superficiais de como lidar com o texto e, consequentemente, a uma tradução totalmente inadequada. (p.20)

Acreditar que traduzir seja simplesmente transpor um texto de um língua para outra é uma crença também discutida no já mencionado trabalho de Milton (2000), que coletou dados por meio de um questionário aplicado a alunos do Curso de Tradução da Faculdade Ibero-Americana de São Paulo (hoje Anhanguera), do Curso de Tradutores da Universidade Estadual Paulista (UNESP), campus São José do Rio Preto do Estado de São Paulo, e do Curso Especial em Tradução da USP de São Paulo. Foram examinadas as razões pelas quais estudantes escolhem cursos universitários em tradução. Segundo o autor, com o grande crescimento dessa área nos anos de 1970, foi impossível para as escolas/faculdades controlar o nível dos ingressantes com um bom domínio da língua estrangeira, já que o lucro das faculdades particulares depende do número de alunos por sala, segundo Milton (op.cit).

Para o pesquisador, a escolha mais popular pelos cursos supracitados está ligada à possibilidade de melhorar as habilidades linguísticas e ter contato com culturas estrangeiras. Em segundo lugar, à qualidade do próprio curso de acordo com publicações como o Guia do Estudante.

Outros dados foram analisados por Milton (2000) a partir de questionários coletados junto a tradutores profissionais consultados via lista online de tradutores, a tradprt@onelist.com. Nesta lista, Milton (op.cit.) lançou uma pergunta que se referia a que tipo de treinamento seria mais apropriado para tradutores no Brasil e quais os problemas observados nos cursos de tradução oferecidos pelas faculdades.

Alguns dos respondentes afirmaram que era preferível obter primeiramente uma graduação em áreas tais como direito, medicina ou engenharia, para, só então, procederse à especialização em tradução. Outros tradutores responderam que acreditavam que uma graduação em tradução era uma perda de tempo e que cursos pontuais, de curta duração, feitos paralelamente ou após a conclusão de um curso de graduação em outra área, seriam muito mais produtivos. 
Em relação a alguns problemas dos cursos de graduação em tradução existentes no Brasil, Milton (2000) detectou junto aos entrevistados que a proximidade entre os cursos de Tradução e Letras é um eterno problema, podendo-se afirmar que, ainda hoje, muitos desses cursos de Tradução estão organizados nos moldes de cursos de Letras, com grande parte do currículo dedicado à Literatura e Linguística e com pouca ênfase na tradução técnica. Os entrevistados por Milton (op.cit.) apontaram ainda que os cursos de graduação em tradução não preparam o aluno para o mercado de trabalho, não oferecem treinamento para a utilização de softwares e não orientam o aluno na montagem de uma microempresa, além de não relacionarem adequadamente o conteúdo dos cursos com a realidade da prática tradutória.

Milton (2000) concluiu que, por desconhecimento em relação à complexidade da área de tradução, uma minoria ingressou no curso especificamente para tornar-se tradutor/intérprete ou para aperfeiçoar habilidades de tradução.

Giacomini (2005) constatou que os alunos ingressantes de um Curso de Graduação em Tradução de uma universidade particular do interior do Estado de São Paulo esperam, como no estudo de Milton (2000), aperfeiçoar o idioma, adquirir e aperfeiçoar conhecimentos linguísticos relacionados à língua materna e adquirir conhecimentos culturais, sendo que uma minoria espera adquirir técnicas para a realização de pesquisas, além de técnicas e teorias de tradução, ética profissional e competência para outros ofícios do tradutor.

Mais tarde, o texto de Guerini e Torres (2006), pautado na discussão sobre perspectivas educacionais, mostra que até há bem pouco tempo o ensino de tradução no país era tradicionalmente desenvolvido em nível de graduação e que nos dias de hoje ganha corpo em nível de pós-graduação, evidenciando o crescimento da área de tradução graças ao volume de trabalhos que têm sido publicados, dando chance a interessados na área de consultar os sítios virtuais das universidades e ter acesso a suas publicações, daí a importância de estudos que foquem a sala de aula.

Oliveira (2006) afirma que o aumento das instituições que ofertam cursos de tradução acaba por exigir que se pense nas relações de ensino e aprendizagem de teoria e prática de tradução, sendo a sala de aula um espaço importante para pesquisas.

Para a autora, a prática de tradução em sala de aula não é atividade autônoma e independente do ambiente cultural em que está inserida, uma vez que se desenvolve da forma permitida por essas crenças e pelos papéis assumidos pelas pessoas envolvidas 
(professor e alunos), os quais são definidos, novamente, pelas expectativas desses mesmos indivíduos. Segundo Oliveira (2006):

O estudo de pressupostos que esses alunos têm sobre sua área de atuação, que envolvem inclusive aspectos que podem ter reflexos após o período de formação, no momento de celebrações de contratos de trabalho, por exemplo, pode ser de muita valia para que respostas possam ser dadas a perguntas como "é possível aprender tradução?", "que habilidades são necessárias na formação de um tradutor?", "como trabalhar com tradução em sala de aula" e, finalmente, "o que mudou depois de tanta discussão teórica sobre a tradução?". (p. 83)

Martins (2006) também considera que a busca por pressupostos que definem a tradução dentro e fora da sala de aula são de crucial importância. A autora, com base em Arrojo (1993)33, explica que, no que diz respeito à relação entre o tradutor e o texto de partida, a pedagogia tradicional, na sua preocupação em eliminar as divergências e em nome do que é "objetivamente" correto e adequado, acaba por impor uma leitura autoritária do texto a ser traduzido, uma determinada concepção de tradução e uma única maneira "certa" de realizar a atividade. O novo desafio que surgiu nos últimos tempos é precisamente a aceitação e a valorização da diversidade, juntamente com a reflexão crítica envolvida no processo de se avaliar estratégias e soluções distintas.

Stupiello (2006), fundamentada em sua experiência como professora das disciplinas de Teoria e Prática de Tradução de uma universidade particular da cidade de São José do Rio Preto, Estado de São Paulo, procurou refletir sobre como as idealizações sustentadas pelos alunos ingressantes de um curso universitário de Bacharelado em Letras com Habilitação em Tradutor e Intérprete em relação à profissão e ao papel do tradutor são desmistificadas por um trabalho desenvolvido em aula envolvendo a reflexão sobre tradução vinculada à pós-modernidade, em favor de uma formação efetiva e condizente com a realidade da tarefa de tradutores e intérpretes.

A autora chegou à conclusão de que, partilhando, na maioria das vezes, gosto ou aptidão por línguas, a maior parte daqueles que buscam formação universitária em tradução e interpretação o fazem acreditando que, no ambiente acadêmico, terão acesso a fórmulas ou manuais de tradução que os capacitarão a dominar uma língua estrangeira e, simultaneamente, as regras e os métodos de tradução. Segundo a pesquisadora, é com base nessa crença que os ingressantes do curso, em um primeiro momento, indagam a

\footnotetext{
3 ARROJO, R. Desconstrução, psicanálise e o ensino de tradução. In: ARROJO, R. Tradução, desconstrução e psicanálise. Rio de Janeiro: Imago, 1993. p. 133-148.
} 
pertinência de aulas de Teoria da Tradução, já que acreditam que é somente a prática que vai capacitá-los a realizar traduções de maneira eficaz:

Essa difundida visão sobre a tradução ecoa na maneira como a atividade tradutória é concebida pelos alunos ingressantes que, respondendo a uma pesquisa realizada no início da primeira série sobre suas expectativas com relação ao curso escolhido, têm expressado, em sua grande maioria, a ideia de que traduzir corresponderia a aprender e dominar uma série de regras e recursos que os capacitariam a recuperar sentidos já instituídos na língua de partida e trazê-los à língua de chegada. (Stupiello, 2006, p. 130)

Alves e Magalhães (2006) detectaram crença semelhante ao realizarem uma pesquisa com alunos novatos de uma universidade federal da cidade de Belo Horizonte, em Minas Gerais, investigando o papel do monitoramento cognitivo-discursivo e a metarreflexão na formação de tradutores, discutindo a dificuldade de alguns em se desvencilhar de uma noção arraigada de que todas as entradas lexicais do texto de partida devem ser traduzidas, mesmo diante da incumbência explícita de traduzir o texto para a realidade brasileira.

Segundo os autores, as crenças, por assim dizer como favoráveis ou desfavoráveis ao ensino e à aprendizagem de tradução, ao serem detectadas, precisam ser discutidas com os alunos, para que estes se tornem conscientes delas.

Frota (2006) argumenta que uma forma viável para implementar discussões sobre as crenças que os alunos trazem consigo para a sala de aula de tradução seria a análise de erros de tradução. A autora coloca que:

Em relação aos erros cometidos por ignorância, parece não haver muito o que discutir - erramos porque ignoramos a(s) opção(ões) tradutória(s) adequada(s). O fato de não suscitar muita discussão não implica, entretanto, que o erro por ignorância seja um assunto pouco relevante para se tratar com os alunos. Ao contrário, parece-me importantíssimo, em qualquer curso introdutório de tradução, logo de início, desmistificar possíveis idealizações de que o bom tradutor tudo sabe. Cabe mostrar aos alunos como são frequentes as ocasiões de dúvida e de incompreensão. E mais, temos de mostrar-lhes a importância de se perceber essa ignorância ou desconhecimento. Sem essa percepção, corre-se o risco de errar, pois ela consiste justamente no primeiro passo para a investigação que nos levará ao esclarecimento e à possibilidade de acertar. (p. 142)

Para Frota (2006), no campo da tradução, e a rigor no campo mais amplo da linguagem, há muito já se rompeu com a crença no objetivismo, ou seja, com a ideia de que haja objetos (significados, construções) fixos e estáveis independentemente dos sujeitos que os percebem e julgam. 
A autora ainda coloca que é importante que os nossos alunos saibam, o quanto antes, que no mundo da tradução as nossas escolhas com frequência não podem ser rotuladas como erradas ou certas em termos absolutos:

Todo professor de tradução, várias vezes por aula, se vê confrontado com a seguinte pergunta: "Então, como é que fica?". "Não fica", precisamos responder. Essa pergunta envolve pelo menos uma crença totalmente equivocada, a crença na possibilidade de haver sempre uma tradução ideal, uma única tradução realmente correta. $\mathrm{O}$ aluno mais experiente tende a ir enxergando, com o tempo, a possível coexistência de diferentes opções, equivalentes em qualidade, mas por que não abreviar esse percurso do aluno (que aliás, deve-se dizer, pode não ocorrer se não os alertarmos) e, sobretudo, por que deixar escapar uma situação que constitui objeto de uma discussão tão rica e necessária? (Frota, 2006, p. 147-148)

Para Santos (2011) também é importante mostrar aos alunos que traduzir vai além de transmitir significados e de buscar em dicionários soluções e respostas prontas:

Vale ressaltar, ainda, que a tradução depende das escolhas ou de seleções feitas por cada tradutor, que, concomitantemente, levam em conta aspectos sociais, culturais e, sobretudo, a imagem do leitor/receptor ou do cliente. Dessa forma, os alunos se tornam mais conscientes sobre qual o verdadeiro papel da tradução, e passam a levar em consideração a possibilidade de "recriar" textos e não somente transferir sentidos. Como ponto positivo, os tradutores sentem-se mais autônomos e menos metódicos. Por fim, acreditamos que a avaliação de determinadas crenças acerca desta temática permite aos estudantes e leitores da área uma reflexão sobre como a tradução tem sido vista e avaliada nos cursos de graduação. Além disso, promove uma conscientização sobre o ensino e a prática da tradução. (p. 6)

A partir do arcabouço teórico aqui apresentado percebe-se que as crenças desempenham um papel importante para o êxito do processo de ensino e aprendizagem de tradução.

\section{Procedimentos da Investigação}

O ensino da tradução nos dias de hoje é considerado emergente, principalmente após o advento da Internet (Wyler, 2003), que possibilitou o maior intercâmbio de informações nas mais diferentes línguas. A partir desse fato, há algum tempo, pesquisadores de diversas partes do mundo têm se perguntado como formar tradutores, já que estes necessitam adquirir competências específicas que não se resumem ao conhecimento linguístico (Alves, Magalhães \& Pagano, 2005), e como o conhecimento prévio sobre a área que os alunos trazem para a sala de aula se reflete no processo de ensino e aprendizagem, podendo ainda atingir suas empreitadas tradutórias futuras. 
Trata-se, neste prisma, de uma pesquisa qualitativo-interpretativista, de natureza etnográfica (Pagano, 2000), que visa obter descrições e relatos sobre qual a visão de alunos-ingressantes do ano de 2011 do Curso de Bacharelado em Tradução trazem consigo no que tange à tradução, ao tradutor e à aquisição de línguas.

A pesquisa contou com a participação de 16 alunos-ingressantes do primeiro período do ano de 2011 do recém-criado Curso de Bacharelado em Tradução da Universidade Federal da cidade de Uberlândia, que receberam quatro questionários nãoestruturados, respectivamente QI - Questionário Inicial; Q1 - Concepções da Tradução e do Tradutor; Q2 - Concepções da Aquisição de Línguas; Q3 - Expectativas sobre o ensino da tradução e a prática futura da profissão de tradutor. Os questionários foram elaborados com base em Pagano (2000), Milton (2000), Rodrigues (2004), Giacomini (2005) e Stupiello (2006). Os alunos-ingressantes foram informados a respeito dos objetivos deste trabalho, tendo concordado em participar da pesquisa através da assinatura do Termo de Consentimento Livre e Esclarecido, sendo que suas identidades foram resguardadas com o intuito de assegurar o sigilo e o caráter confidencial da pesquisa.

A aplicação junto aos estudantes do QI visou colher informações pessoais do aluno, seu conhecimento prévio da língua inglesa e os principais motivos que o fizeram optar pelo curso.

O Q1 teve como objetivo verificar a visão do aluno com relação à tradução e ao tradutor, assim como coletar informações concernentes ao ensino e aprendizagem de tradução e de línguas, tendo em vista suas experiências e conceitos sobre tais assuntos.

A aplicação do Q2 objetivou colher as crenças que os alunos trazem consigo com respeito às relações que se estabelecem entre aprender a traduzir e aprender línguas, e como tal relação se reflete nos conceitos e definições que os alunos atribuem para a tradução, para o tradutor e para o conhecedor de idiomas.

O Q3 almejou averiguar as expectativas dos alunos sobre as perspectivas futuras da profissão de tradutor.

Ressalta-se que, segundo o exposto por Pagano (2000), não há respostas certas ou erradas a respeitos das crenças que os alunos ingressantes trazem consigo. O objetivo do uso de questionários não é classificá-las, mas verificar possíveis impactos que as crenças podem exercer no processo de ensino e aprendizagem de tradução.

A partir desta proposta, pretenderam-se alcançar os seguintes objetivos específicos: 
1) Investigar as crenças sobre a tradução e o tradutor que os alunos trazem consigo;

2) Levantar as crenças sobre a aquisição de línguas estrangeiras (neste caso o inglês), uma vez que os resultados já encontrados por outras pesquisas mostram que a maioria dos alunos pensa que traduzir é aperfeiçoar o conhecimento linguístico (Milton, 2000; Giacomini, 2005; Stupiello, 2006);

3) Examinar as expectativas com relação à profissão de tradutor.

A fim de operacionalizar os objetivos específicos, esta investigação busca responder às seguintes perguntas de pesquisa:

- Quais são as crenças dos alunos-tradutores sobre a tradução e o tradutor?

- Quais são as crenças dos alunos-tradutores sobre a aquisição de línguas e do conhecimento sobre tradução?

- Quais são as expectativas destes alunos com relação ao ensino de tradução e à prática futura da profissão?

\section{Resultados e Discussão}

Os resultados a seguir referem-se à coleta de dados do Questionário Inicial (QI) que, como especificado na metodologia, tem como objetivo verificar a visão do aluno com relação à tradução e ao tradutor, assim como coletar informações básicas concernentes ao ensino e à aprendizagem de tradução e de línguas, tendo em vista suas experiências e conceitos sobre tais assuntos.

O QI é constituído de seis perguntas fechadas (de 1 a 6) e de uma pergunta aberta (7).

Conforme mencionado, este estudo contou com a participação de 16 alunos cursando o primeiro período do curso, iniciado no $1^{\circ}$ semestre letivo de 2011 , sendo seis do sexo masculino e 10 do sexo feminino, com idade entre 17 e 31 anos.

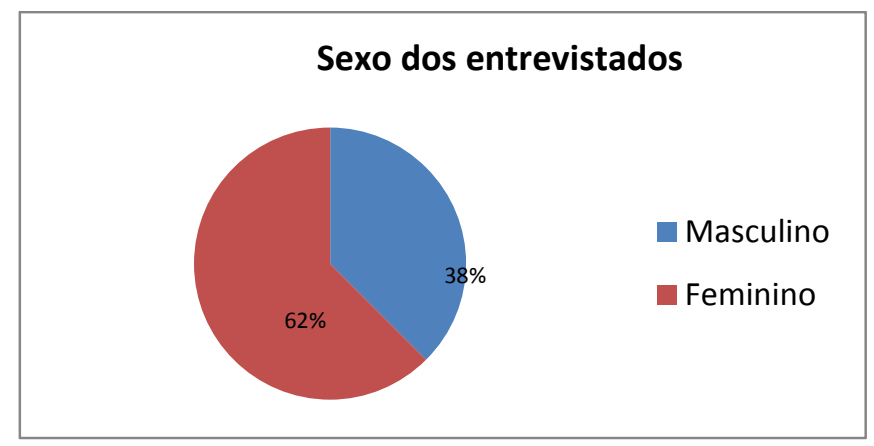




\section{Gráfico 1: Sexo dos entrevistados}

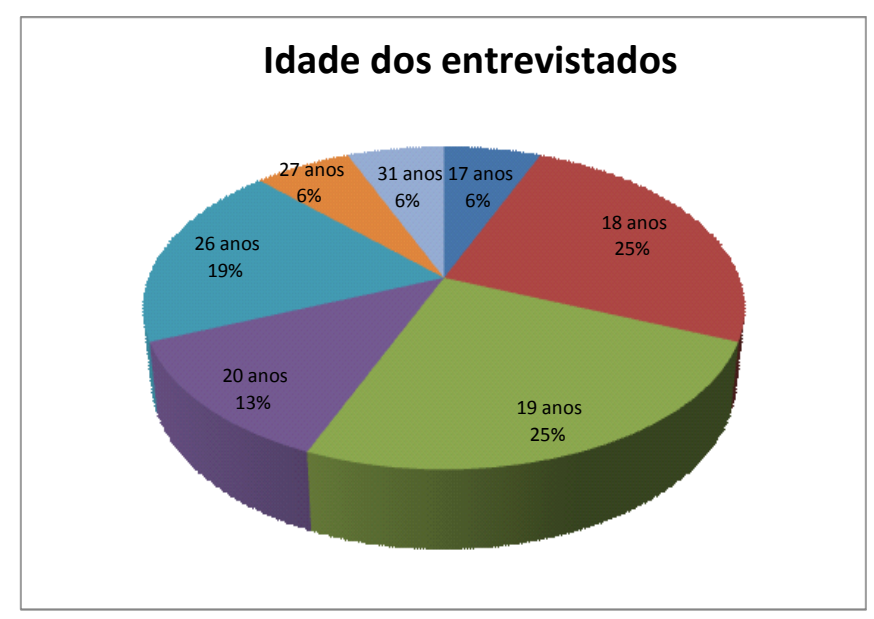

Gráfico 2: Idade dos Entrevistados

Com relação aos dados que estão relacionados aos cursos específicos de Língua Inglesa em institutos de idiomas, verificou-se que quase $100 \%$ dos alunos possuem experiência com a língua inglesa, sendo que um participante relatou nunca ter tido contato formal com a língua. Outro participante relatou desconhecer a data em que iniciou seus estudos sobre o idioma.

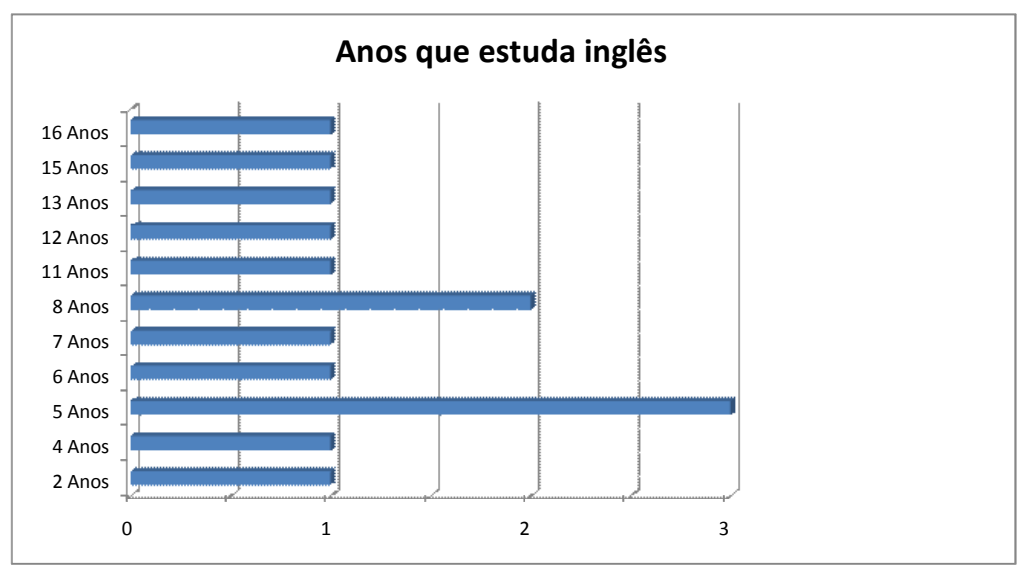

Gráfico 3: Experiência com a língua inglesa

Dos participantes que declararam possuir estudos na língua inglesa, ressalta-se que $50 \%$ relataram possuir nível avançado e outros 50\%, nível intermediário no idioma.

Dos participantes que declararam possuir estudos na língua inglesa, ressalta-se que 8 relataram possuir nível avançado e outros 8 , nível intermediário no idioma. 
ESQUEDA \& OLIVEIRA - Crenças e concepções do tradutor em formação

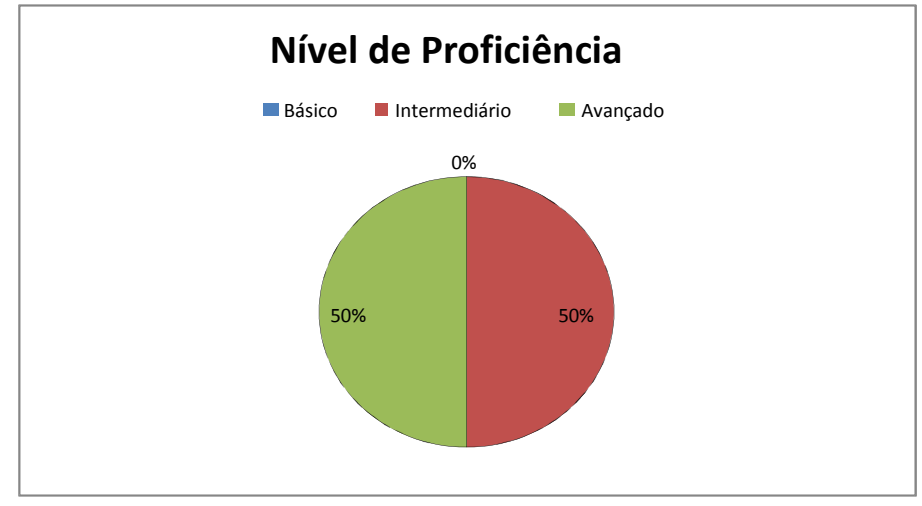

Gráfico 4: Nível de Proficiência

Verificou-se que $80 \%$ frequentaram cursos de inglês em institutos de línguas e $20 \%$ aprenderam o idioma através de outras formas. Um participante relatou ter tido uma experiência em país estrangeiro, tendo feito curso inglês na Westchester High School, em Los Angeles, Califórnia, nos Estados Unidos, onde o inglês é a primeira língua (sendo que este aluno relatou ter residido e estudado neste país).

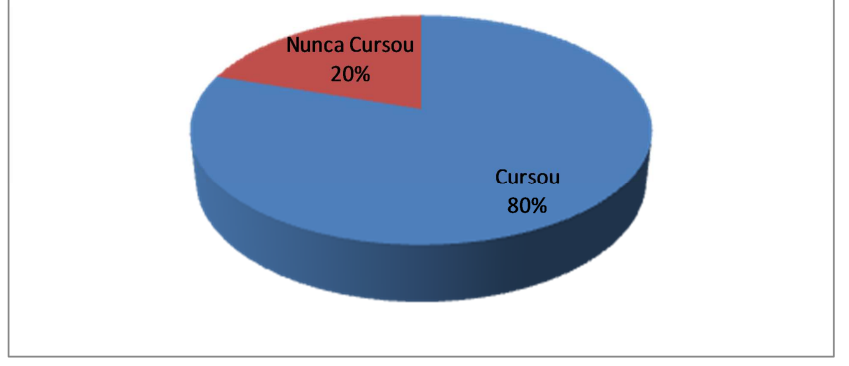

Gráfico 5: Instituições/Cursos de Inglês

Apesar da experiência com o idioma, destaca-se que apenas $13 \%$ dos participantes declaram ter participado de algum evento acadêmica da área de tradução, como seminários, cursos de aperfeiçoamento, congressos, oficinas, entre outros. 


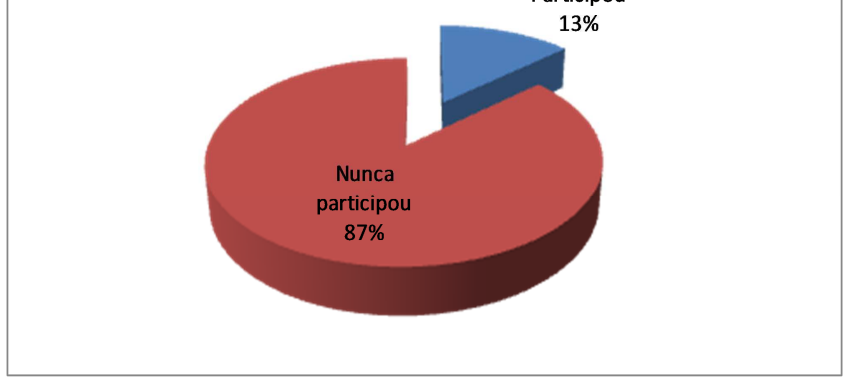

Gráfico 6: Participação de eventos na área

Com relação à pergunta 7 do QI, sobre quais fatores influenciaram a escolha pelo Curso Superior em Tradução, dos 16 respondentes, apenas dois apresentaram motivações diferentes para a escolha do curso. Quatorze alunos responderam ter escolhido o curso de tradução devido ao desejo de aperfeiçoar a língua inglesa, ao passo que apenas um respondente afirmou ter escolhido o curso devido ao seu conhecimento prévio sobre tradução adquirido em congressos da área. Outro respondente referiu-se ao desejo de não somente dedicar-se à língua, mas também à cultura.

As informações coletadas no QI buscaram levantar dados que possibilitam tecer o perfil dos alunos-tradutores participantes deste estudo, isto é, o de ingressantes que, em sua maioria, desejam aperfeiçoar a língua estrangeira, neste caso, o inglês, perfil este semelhante ao encontrado por Milton (2000), Rodrigues (2004), Giacomini (2005) e Stupiello (2006), o que indica que, apesar da expansão da área e acesso às publicações sobre a mesma pelos sítios virtuais das universidades que ofertam o curso (Guerini e Torres, 2006), o candidato a ingressante da área de tradução parece possuir as mesmas crenças dos ingressantes da década passada.

Nesse sentido, vale relembrar, segundo Oliveira (2006, p.15), que "as crenças têm impacto social, influenciando o que o restante da comunidade pensa sobre os tradutores e sendo influenciada por essas opiniões".

A seguir, outras informações foram levantadas através dos dados coletados dos Q1, Q2 e Q3. Alguns dos resultados serão também explicitados por meio de gráficos, sendo que outros serão resumidos por questões de espaço.

O Q1 tem como proposta coletar junto aos ingressantes informações concernentes à compreensão destes sobre o que é tradução, suas percepções do que seja um bom tradutor e uma boa tradução; se acreditam que teorias e estratégias de tradução 
podem ser necessárias no processo tradutório; se a tradução é uma atividade prática que requer conhecimentos da língua estrangeira e um bom dicionário; se com alguns meses de curso, suas percepções com relação à área de Tradução sofreram alguma influência; se, para traduzir, na opinião deles, é necessário ter experiência em países onde se fala a língua alvo; se acreditam que um tradutor deve ter as mesmas habilidades de um professor de idiomas; quais são as habilidades que esperam desenvolver no decorrer do curso e quais habilidades esperam ter adquirido ao final do curso (Pagano, 2000).

Sobre a primeira pergunta, "O que é tradução?", dos 16 ingressantes, 14 responderam que tradução consiste na transmissão de informações de uma língua para outra; um respondeu que é uma forma de globalização e outro aluno respondeu que é um meio de compreender melhor dois idiomas.

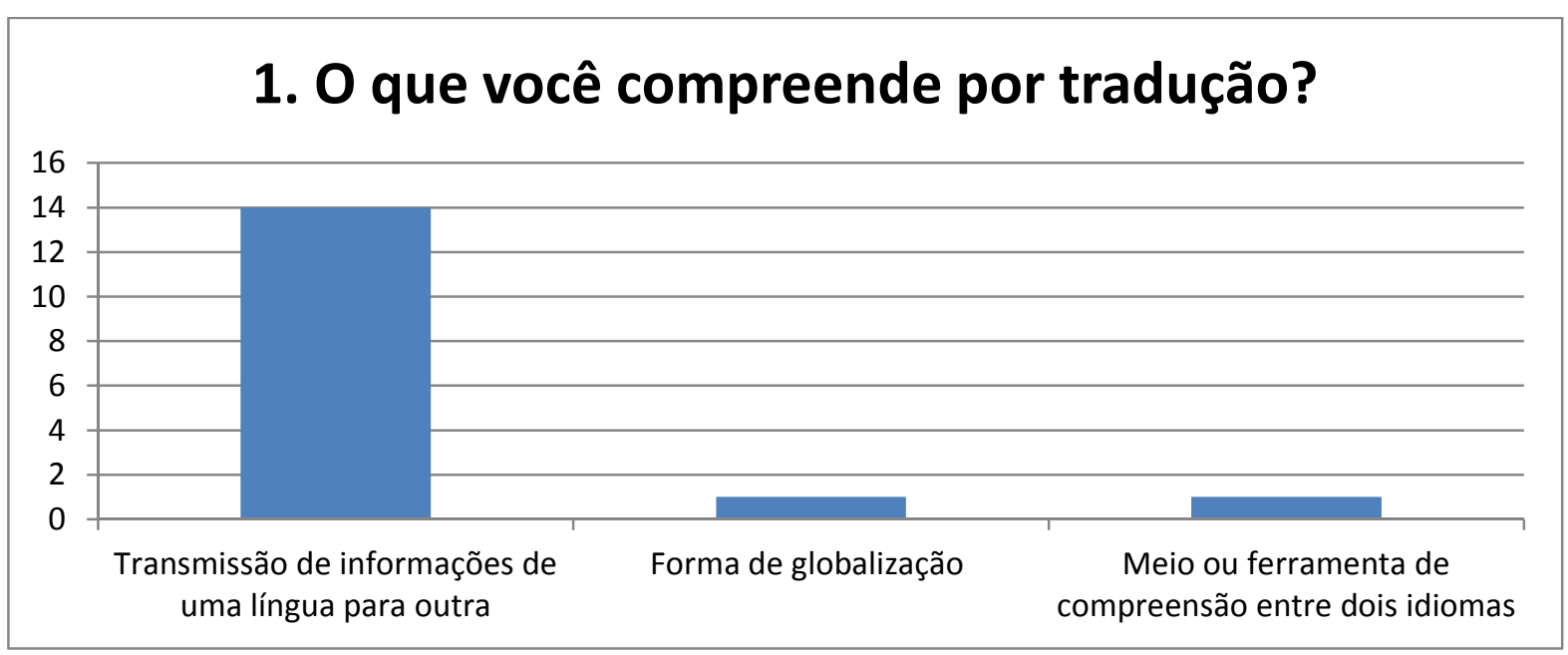

Gráfico 7: "O que você compreende por tradução?"

Com relação às percepções dos ingressantes sobre o bom tradutor e a boa tradução, dos 16 respondentes, cinco consideram que um bom tradutor é aquele que possui conhecimento linguístico; quatro responderam que o bom tradutor deve se preocupar com o leitor; três responderam que o bom tradutor é fiel ao texto original; um respondente afirmou que o bom tradutor é aquele que tem paciência para encontrar os vocábulos mais adequados; outro ingressante respondeu que o tradutor deve ser capaz de solucionar problemas da tradução, tornando-a fluente; um ingressante afirmou que o tradutor é aquele que se dedica ao que faz; e outro, que um bom tradutor busca ferramentas para auxiliá-lo, tornando-se um eterno aprendiz.

Conforme mostra o gráfico a seguir, sobre a percepção dos respondentes quanto à boa tradução, 11 responderam que a boa tradução é aquela que não "foge" da ideia do 
original e quatro responderam que a tradução deve soar natural, fluente e clara. Um respondente afirmou que a tradução é uma forma de reduzir o impacto entre original e tradução.

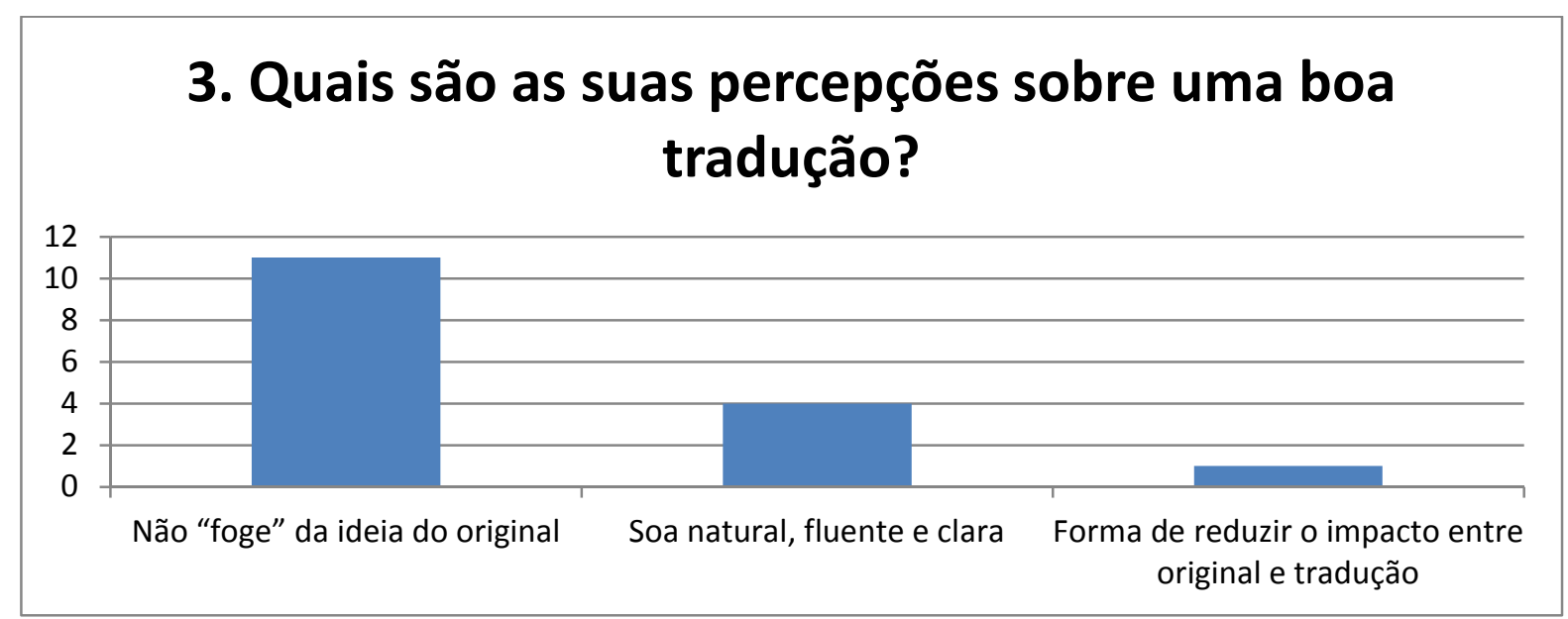

Gráfico 8: “Quais são as suas percepções sobre uma boa tradução?”

Com relação às teorias e estratégias de tradução que podem ser necessárias no processo tradutório, dos 16, 15 responderam que o tradutor necessita de teorias e estratégias de tradução para se familiarizar com os problemas da área. Dentre estes 15, um aluno completou a ideia afirmando que conhecer apenas a língua pode deixar o texto mais pobre. Apenas um aluno afirmou que a teoria e as estratégias de tradução não são necessárias, apesar de poderem facilitar o processo.

No que tange à crença de que a tradução é uma atividade que requer conhecimento linguístico e um bom dicionário, dos 16 respondentes, 12 afirmaram que a tradução é, sim, uma atividade prática que requer o conhecimento da língua estrangeira e um bom dicionário. Um aluno respondeu que a tradução depende de conhecimentos linguísticos e bons dicionários, mas também que só isso não basta, sem mencionar quais outros fatores condicionam a atividade de tradução. Três alunos responderam que a tradução não depende apenas de conhecimentos linguísticos e dicionários, mas de estratégias, teorias, pesquisas e outros fatores.

Sobre a questão da vivência no exterior servir de conhecimento para o tradutor, 14 alunos responderam que não é necessário viver no país onde se fala a língua alvo para traduzir bem. Dois afirmaram que sim.

Quatorze respondentes afirmaram que o tradutor não deve ter as mesmas habilidades de um professor de idiomas. Apenas dois respondentes afirmaram que as habilidades destes dois profissionais são coincidentes, embora completando a ideia de 
que o tradutor deve ser "mais" do que professor. No entanto, os respondentes não especificaram as diferenças.

Com relação às expectativas dos ingressantes sobre quais habilidades pretendem desenvolver no decorrer do curso, dos 16 alunos, cinco responderam que desejam aperfeiçoar a língua estrangeira e materna, melhorando a escrita e a fala em ambas. Cinco ingressantes buscam aprender habilidades e estratégias para a realização de uma boa tradução. Dois alunos afirmaram que esperam conhecer melhor as teorias e técnicas da tradução. Um aluno afirmou que espera compreender e refletir sobre o público que receberá a tradução, bem como sobre o produto final da tradução. Um aluno espera ter uma melhor percepção sobre a tradução para fazer um trabalho melhor. Um aluno espera ter capacidade de saber utilizar os processos que ajudam no trabalho de tradução. Apenas um aluno não respondeu.

Sobre quais habilidades os ingressantes desejam ter desenvolvido após o término do curso, 15 alunos responderam que esperam ter adquirido conhecimento linguístico, teórico e técnicas de tradução que os deixem prontos para o mercado. Conhecer as línguas materna e estrangeira, ler e escrever bem em ambas, também foram habilidades citadas pelos alunos. Apenas um aluno não respondeu.

Como nos estudos de Milton (2000), Rodrigues (2004), Giacomini (2005) e Stupiello (2006), os respondentes desta pesquisa percebem a tradução como transmissão de informações de uma língua para outra, e que o profissional responsável por este processo é aquele que possuiu conhecimento linguístico e que não "foge" da ideia apresentada no original em sua tradução, considerando que o tradutor necessita de técnicas de tradução, como, por exemplo, um bom dicionário. Os respondentes, em sua maioria, conforme encontrado por Milton (2000), também desejam aperfeiçoar a língua estrangeira ao longo do curso, tendo como expectativa ter adquirido, até o final deste, maior conhecimento linguístico, teorias e técnicas de tradução.

Quanto à última pergunta do Q1, “Com estes meses de curso, sua percepção com relação à área de Tradução sofreu alguma influência?", apenas dois dos 16 alunos responderam que suas percepções continuam as mesmas. Quatorze alunos mencionaram, no entanto, que o curso alterou em parte suas percepções sobre a área de Tradução. Antes de ingressar no curso, os respondentes afirmaram ter uma visão muito ingênua e superficial da tradução e que, para eles, traduzir era simplesmente passar um texto de uma língua para outra. 
O Q2, como já mencionado, tem o intuito de colher as crenças que os alunos trazem consigo com respeito às relações que se estabelecem entre aprender a traduzir e aprender línguas, e como tal relação se reflete nos conceitos e definições que os alunos atribuem para a tradução, para o tradutor e para o conhecedor de idiomas.

Quando questionados sobre quais conteúdos são mais importantes a serem enfatizados no ensino de línguas, dos 16 alunos, oito citaram a gramática; dois, a cultura; um citou temas variados (provavelmente se referindo aos gêneros e tipos textuais); outro aluno citou as marcas textuais; dois referiram-se às aulas de conversação e pronúncia; um aluno mencionou que espera que o curso enfatize "coisas habituais"; outro afirmou que deve ser ensinado o básico e o restante deve ser buscado pelo aluno.

Sobre os objetivos de se estudar um idioma, dos 16 alunos, três mencionaram a obtenção de conhecimentos culturais; dois, o aperfeiçoamento da conversação em línguas estrangeiras; três disseram que o objetivo é obter maior conhecimento linguístico; um aluno citou que o objetivo de se aprender línguas tem a ver com as exigências do mercado de trabalho; outro aluno mencionou o fato de se estudar um idioma estrangeiro para ganhar dinheiro; dois disseram que o conhecimento de um idioma estrangeiro serve para se conseguir emprego; dois mencionaram que se estuda um idioma para ensiná-lo; um aluno mencionou que o objetivo é entender outras línguas; outro aluno mencionou o fato de se estudar um idioma para o enriquecimento pessoal.

Sobre quais habilidades linguísticas (audiocompreensão, produção oral, leitura, escrita) devem ser desenvolvidas no decorrer do Curso de Tradução, dos 16 alunos, três disseram que as habilidades de leitura e escrita deveriam ser desenvolvidas junto a tradutores, e a audiocompreensão e a fala, junto a intérpretes; dez alunos disseram que todas as habilidades de leitura, escrita, audiocompreensão e fala deveriam ser desenvolvidas, até mesmo para que o aluno possa escolher o quê fazer no futuro; dois alunos disseram que somente a leitura e a escrita deveriam ser desenvolvidas; um aluno não soube responder.

Com respeito à pergunta: "O que é um bom professor de línguas e um bom professor de tradução?", dos 16 alunos, um respondeu que o professor de línguas e de tradução deve ter conhecimentos ligados à tradução; dez responderam que o conhecimento do professor deve estar atrelado à gramática e às técnicas de tradução; um respondente mencionou que o professor deve saber diferenciar conceitos; um aluno respondeu que o professor deve "contagiar" a aula; outro respondeu que o professor 
deve indicar caminhos para que o aluno produza seu conhecimento; um respondeu que o professor de línguas e de tradução deve ter conhecimentos culturais e dos autores dos originais a serem traduzidos; um não soube responder.

Ressalta-se, mais uma vez, que neste universo investigado, o aluno-tradutor relaciona sua crença sobre aperfeiçoar o idioma com o perfil do professor de tradução. Percebe-se, portanto, a valorização dos conhecimentos linguísticos em detrimento dos conhecimentos sobre a tradução por parte da maioria dos respondentes.

Finalmente, o Q3 objetiva averiguar as expectativas dos alunos sobre as perspectivas futuras da profissão de tradutor e de seu ensino.

Quatro alunos afirmaram que se devem conhecer os trabalhos feitos pelo tradutor; quatro mencioram que o tradutor deve conhecer várias áreas, para facilitar sua contratação; três mencionaram os critérios estabelecidos pelos contratantes são importantes; um aluno mencionou que a experiência do tradutor deve contar no momento da contratação; quatro alunos não souberam responder.

Sobre a pergunta: "Na sua opinião, o que um tradutor competente deve ser capaz de realizar?", dos 16 alunos, um respondeu que o tradutor competente é o que valoriza o leitor; quatro responderam que o tradutor competente é o que não deixa o leitor perceber que se trata de uma tradução; seis responderam que é aquele que realiza uma boa tradução; um aluno mencionou que uma boa tradução não tem erros; um aluno afirmou que a boa tradução não perde o sentido; dois mencionaram que o tradutor competente realiza uma boa transferência de significados; um aluno não respondeu.

\section{Conclusão}

As informações coletadas no Q1 apresentam dados importantes que podem compor a resposta da pergunta de pesquisa 1: Quais são as crenças dos alunostradutores sobre a tradução e o tradutor; sobre a boa tradução e o bom tradutor?

Com base nos dados coletados, a maioria dos ingressantes possui a crença de que a tradução é a transferência de informações de uma língua para outra, não devendo "fugir" do original; que a atividade de tradução requer conhecimento linguístico; de que o tradutor deve ter as mesmas habilidades de um professor de idiomas, sendo que a maioria dos ingressantes expressou o desejo de aperfeiçoar e adquirir mais conhecimentos linguísticos.

Embora alguns dados referentes ao Q1 também mostrem a crença do aluno de que a teoria de tradução é importante para familiarizar o tradutor com seu objeto de 
estudo e trabalho, e de que não é necessário viver no país estrangeiro onde se fala a língua que o tradutor irá traduzir, o aluno ingressante ainda percebe a tradução como transferência de significados, como sendo uma atividade simples que pode ser executada com bons dicionários e conhecimento linguístico.

Os dados coletados no Q2 apresentam respostas à pergunta de pesquisa 2: Quais são as crenças dos alunos-tradutores sobre a aquisição, o ensino e a aprendizagem de línguas?

Em sua maioria, os ingressantes possuem a crença de que o ensino e a aprendizagem de línguas estão atrelados à aquisição de conhecimentos gramaticais do idioma, embora enfatizando que questões culturais e mercadológicas estejam imbricadas no processo de se aprender e ensinar uma língua estrangeira. A maioria dos alunos mencionou que todas as habilidades da língua (leitura, escrita, fala e audiocompreensão) devem ser ensinadas. Ressalta-se aqui a ideia expressa pelos alunos de que o tradutor deve ter pleno domínio do idioma, isto é, dominar todas as habilidades e regras da língua. Segundo Pagano (2000), o domínio de uma língua estrangeira não basta para se realizar uma boa tradução. Os conhecimentos linguísticos, juntamente com o conhecimento cultural, técnico, e as habilidades apropriadas para o exercício da recriação de um texto podem viabilizar uma tradução mais satisfatória.

Com relação à crença sobre o bom professor de línguas e tradução, a maioria dos ingressantes ressaltou o fato de que o professor deve ter conhecimentos gramaticais. Ou seja, os dados mostram que os ingressantes trazem consigo um conceito de professor como transmissor de componentes gramaticais de uma língua. Percebe-se que apenas um aluno respondeu que o professor deve indicar caminhos para que o aluno produza seu próprio conhecimento. A maior parte dos alunos-ingressantes não se vê como sujeito e agente no processo de formação, depositando na instrução gramatical do professor sua fonte de conhecimento.

Como resposta à pergunta de pesquisa 3: "Quais são as expectativas destes alunos com relação ao ensino de tradução e à prática futura da profissão?", pôde-se constatar, através dos dados coletados, que os ingressantes, em sua maioria, possuem as seguintes expectativas: de adquirirem conhecimento das várias áreas da tradução, para que sua contratação possa ser facilitada; de que ser fiel ao texto original é o indicador de uma boa e aceitável tradução; de que o tradutor competente não deixa o público perceber que se trata de uma tradução; de que a teoria é importante e auxilia a prática, sem mencionarem exatamente como isso ocorre; de que conhecimentos culturais são 
importantes para se manter a fidelidade ao texto original; de que o leitor em prospecção é o que guia a boa tradução.

Por meio da última questão deste questionário, pôde-se constatar, ainda, que os alunos esperam que o bom professor lhes transmita conhecimentos verdadeiros adquiridos por ele (professor) durante sua trajetória profissional e acadêmica, sem mencionarem no que consistem tais conhecimentos verdadeiros, embora alguns alunos tenham aludido ao fato de que o professor deve atuar como instigador.

Como já exposto por Pagano (2000) e corroborado neste trabalho, não há respostas certas ou erradas a respeitos das crenças que os alunos ingressantes trazem consigo. Almejou-se o desvendamento dessas crenças no contexto investigado, identificando possíveis ações e procedimentos que contribuam para a formação consciente e autônoma de futuros tradutores, principalmente no que diz respeito aos papeis de professores e alunos na sala de aula de tradução.

Destaca-se que estes dados são bastante similares aos encontrados por Milton (2000), Rodrigues (2004), Giacomini (2005), Stupiello (2006), o que nos leva a constatar como verdadeiras as argumentações de Lages (1992) e Katan (2004), de que estudar as crenças, pensamentos, expectativas, concepções, ou nome semelhante que se queira atribuir à temática, é de suma importância para a construção social e acadêmica do que se pensa sobre a tradução e o tradutor e de como se ensina e se aprende a traduzir.

\section{Referências}

AlveS, F.; MAGAlHÃES, C.; PAGANO, A. Competências em Tradução. Belo Horizonte: Editora da UFMG, 2005.

ALVES, F.; MAGAlHÃES, C. Investigando o Papel do Monitoramento CognitivoDiscursivo e da Meta-Reflexão na Formação de Tradutores. Cadernos de Tradução, n. 17, p. 71-127, 2006.

BARCELOS, A.M.F. A cultura de aprender língua estrangeira (inglês) de alunos

formandos de Letras. 1995. Dissertação (Mestrado em Linguística) - Instituto de Estudos da Linguagem - IEL, UNICAMP, Campinas.

BARCElOS, A.M.; VIEIRA-ABRAHÃO, M.H. (Orgs.). Crenças e Ensino de Línguas - foco no professor, no aluno e na formação de professores. Campinas, SP: Pontes Editores, 2006. 
CARVALHO, V.C.P.S. A aprendizagem de língua estrangeira sob a ótica de alunos de Letras: Crenças e Mitos. Belo Horizonte: Faculdade de Letras UFMG, 2000. Dissertação (Mestrado em Linguística Aplicada ao Ensino de Línguas Estrangeiras) - Faculdade de Letras UFMG, Belo Horizonte.

ESQUEDA, M.D.; FRATINE, R.V. Crenças. Reflexões sobre ensino e aprendizagem de línguas estrangeiras: Crenças de alunos ingressantes do curso de Letras-Inglês. In: SILVA, K.A. da. Crenças, discursos \& Linguagem. Vol. II. Campinas, SP: Pontes Editores, 2011.

FERREIRA, A.C. Desafio de ensinar-aprender matemática no curso noturno: um estudo das crenças de estudantes de uma escola publica de Belo Horizonte. 1998. Dissertação de Mestrado (Mestrado em Educação Matemática) Universidade Estadual de Campinas, Faculdade de Educação, Campinas.

FROTA, M. P. Erros e lapsos de tradução: um tema para o ensino. In: PAGANO e VASCONCELOS (Orgs.). Cadernos de Tradução, v. XVII, p. 141-156, 2006.

GIACOMINI, K. Competência linguístico-comunicativa e competência tradutória: expectativas futuras na formação de tradutores. 2005. Trabalho de Conclusão de Curso (Graduação em Tradução) - Universidade do Sagrado Coração, Bauru.

GIMENEZ, T. Learners becoming teachers: An exploratory study of beliefs held by prospective and practising EFL teachers in Brazil. 1994. Tese (Doutorado). Lancaster University, Lancaster.

GUERINI, A.; TORRES, M.H. A Pós-Graduação em Estudos da Tradução da UFSC: Trajetórias e Projeções. Cadernos de Tradução, v. XVII, p. 19-24, 2006.

KATAN, D. Translating Cultures. Introduction to Translators, Interpreters and Mediators. 2nd edition. Manchester, UK: St Jerome, 2004.

LAGES, S.K. O tradutor e a melancolia. Trabalhos em Linguística Aplicada, n.19, p. 91-97, 1992.

MAGALHÃES, C. O tradutor segundo o tradutor brasileiro. In: Anais das VIII e IX Semanas de Estudos Germânicos do Departamento de Letras Germânicas da UFMG. Belo Horizonte: FALE/UFMG, p. 136-143, 1991/1992.

MARTINS, M.A.P. Novos desafios na formação de tradutores. Cadernos de Tradução, v. XVII, p. 25-44, 2006.

MILTON, J. Para ser tradutor ou para melhorar a língua? Por que estudantes brasileiros escolhem cursos de tradução? Revista TRADTERM, v. 6, p. 83-105, 2000. 
MOTTA, Cristina Dalva Van Berghem. Resumo Expandido: o papel psicológico da História da Matemática no processo de ensino-aprendizagem. In: Anais do Simpósio Internacional do Adolescente, 2005, São Paulo (SP) [online]. Disponível em $<$ http://www.proceedings.scielo.br/scielo.php?script=sci_arttext\&pid=MSC000000 0082005000200056\&lng=en\&nrm=iso> . Acesso em: 05 Ago 2013.

NICOLAIDES, C.; FERNANDES, V. Crenças e atitudes que marcam o desenvolvimento da autonomia no aprendizado de língua estrangeira. The ESPecialist, v.23, n.1, p.75-99, 2002.

OLIVEIRA, A. R. Crenças dos alunos em sala de aula: se a tradução fosse... Línguas e Letras. vol. $7 \mathrm{n}^{\circ} 12,1^{\circ}$ sem. 2006. p. 81-97.

PAGANO, A. Crenças sobre a tradução e o tradutor: revisão e perspectivas para novos planos de ação. In: ALVES, F.; MAGALHÃES, C.; PAGANO, A. Traduzir com autonomia: estratégias para o tradutor em formação. São Paulo: Editora Contexto, 2000. p. 9-28.

PYM, A. Epistemological problems in translation and its teaching - a seminar for thinking students. Calaceit: Ediciones Caminade, 1993.

RODRIGUES, C. C. O ensino da tradução: entre a possibilidade e a necessidade. In: Anais dos Estudos Linguísticos XXXIII, p. 79-83, 2004.

RODRIGUEZ, B. L. et al. O Papel da Química: as Múltiplas Representações na Ótica de Sujeitos Diversos. In: Anais do Seminário Educação e o novo milênio. Mariana/MG: Universidade Federal de Ouro Preto, 2000. Disponível em: <http://www.geocities.com/nepsi_ufop/breno.htm>. Acesso em: 08 Mai. 2010.

SANTOS, T. J. P. dos. Crenças sobre o ensino e a prática da tradução. Revista Fronteira Digital. Cáceres, MT: Universidade Estadual do Mato Grosso. Ano II - n. ${ }^{\circ}$ 03/Jan.-Ago. 2011. p.150-156. Disponível em: <http://www.unemat.br/revistas/fronteiradigital/docs/artigos/n3_2011/fronteira_digital_ n3_2011_art_4.pdf>. Acesso em: 08 Nov. 2011.

SILVA, K.A. Crenças e aglomerados de crenças de alunos ingressantes de Letras (inglês). 2005. 243 p. Dissertação (Mestrado em Linguística Aplicada) - Instituto de Estudos da Linguagem - IEL, UNICAMP, Campinas.

STUPIELLO, E. N. de A. O ideal e o real no ensino universitário da tradução. In: PAGANO e VASCONCELOS (Orgs.). Cadernos de tradução, v. XVII, p. 129139, 2006. 
ESQUEDA \& OLIVEIRA - Crenças e concepções do tradutor em formação

VIANA, N. A desconstrução dos mitos na aprendizagem de língua estrangeira.

Uberlândia: Departamento de Letras da Universidade Federal de Uberlândia, 1993.

WYLER, L. Línguas, Poetas e Bacharéis. Rio de Janeiro: Rocco, 2003. 